\title{
The Role of National Culture Values and Trust in Online Sharing Hospitality Platform Acceptance
}

\author{
Cong Zhang, University of Wisconsin, Milwaukee, USA \\ Mark Srite, University of Wisconsin, Milwaukee, USA \\ (iD https://orcid.org/0000-0002-8950-9545
}

\begin{abstract}
The sharing economy, as an emerging business model, has grown greatly in the last decade. However, the acceptance rate of the sharing economy varies from country to country. Researchers have noted the importance of cultural values on technology acceptance in different countries. This study investigates the influence of national cultural values and trust on the acceptance of online sharing hospitality platforms by users in the US and China via a survey methodology. The four espoused national cultural dimensions of individualism/collectivism, uncertainty avoidance, masculinity/femininity, and power distance were measured at the individual level. Extending from the technology acceptance model (TAM), the research model integrates both direct and moderating effects of culture and trust. The two constructs of trust both have significant direct effects on intention to use. Uncertainty avoidance has a significant moderating effect. The results emphasize the importance of trust and cultural values, especially uncertainty avoidance in online hospitality platforms adoption.
\end{abstract}

\section{KEYWORDS}

National Culture, Online Sharing Hospitality Platforms, Sharing Economy, Technology Acceptance, Trust

\section{INTRODUCTION}

The sharing economy represents the embodiment of the peer-to-peer-based activity of obtaining, giving, or sharing the access to goods and services, coordinated through community-based online services (Hamari et al., 2016). Largely facilitated by the development of information technology, the sharing economy has proliferated over the last decade. It is estimated that the number of adult users of the sharing economy in the US reached 44.8 million in 2016, and the number is expected to grow to 86.5 million by 2021 (Lock, 2019). As predicted, the total value of the global sharing economy will increase to about 335 billion US dollars by 2025, from only 15 billion US dollars in 2014 (Mazareanu, 2019). The emergence of the sharing economy has drawn increasingly more attention increasingly in academia. It can be seen in a rapid increase of publications on the sharing economy after 2013 in such diverse areas such as business, computer science, and engineering.

The concept of sharing of resources has a history almost as long as that of humankind (e.g., Belk, 2010; Sundararajan, 2016). However, the current prosperity of the sharing economy is primarily due to the development of digital platforms and other large-scale mediating technologies (Allen, 2017; Belk, 2014; Botsman \& Rogers, 2010). The presence of such technologies separates those businesses

\section{DOI: 10.4018/JGIM.2021050105}

This article, published as an Open Access article on April 16, 2021 in the gold Open Access journal, Journal of Global Information Management (JGIM) (converted to gold Open Access on January 1, 2021), is distributed under the terms of the Creative Commons Attribution 
and communities under the term "sharing economy" from traditional sharing contexts (e.g., Bardhi \& Eckhardt, 2012; Hamari et al., 2016).

From a pure information technology perspective, sharing economy platforms do not significantly differ from other digital platforms. What differentiates them is the novel context for the use of technology. Following the idea of Sutherland and Jarrahi (2018), in this paper, the authors conceptualize sharing economy platforms as sociotechnical systems, whose role and meaning merge in use. Explicitly, instead of treating sharing economy platforms as isolated technological materiality, the authors define the platforms from interactions with human strategies and goals. From the sociotechnical perspective, multiple distinctive affordances can be identified for sharing economy platforms to compare with other digital platforms (Sutherland \& Jarrahi, 2018). For example, they should yield more advanced search and match algorithms to assign proper participants to each other. The platforms should provide enough assurance to allow people to improve or extend interactions across weak and anonymous connections.

Hospitality sharing is an essential industry within the sharing economy, which is enabled by online sharing hospitality platforms. Online hospitality platforms refer to online marketplaces for people to lease or rent short-term lodging. Usually, the platforms do not own any real estate or conduct tours; they act as brokers who receive percentage service fees in conjunction with every booking. In 2015, the number of adult hospitality sharing economy users in the US was 10.3 million, and this number is predicted to grow to about 17 million by the end of 2020 (Statista Research Department, 2016). Airbnb, as the most successful and representative company in this industry, has already had more than 640,000 hosts and 4 million listings by 2018 (Smith, 2018). It has near 5 million lodging listings in 81,000 cities and is in over 191 countries and has facilitated over 300 million check-ins (Airbnb, 2018). As the authors discussed earlier in this section, online sharing hospitality platforms, as one of the most popular groups of sharing economy platforms, should yield multiple distinctive characteristics due to their use context. Therefore, in this paper, the authors are interested in investigating the acceptance problem of online sharing hospitality platforms.

Although the flat world metaphor has gained consensus (Friedman, 2005), cultural conflicts are often treated as the reason for failures in information technology/information systems (IT/IS) projects (Leidner \& Kayworth, 2006) when IT/IS projects fail to fit unfamiliar cultural environments. Wellknown failures were when eBay lost market share to Taobao in China (Ou \& Davison, 2009) and when Google struggled in South Korea (Sang-Hun, 2007). Similarly, the acceptance of online sharing hospitality platforms varies widely from country to country. Airbnb, as one of the most dominant hospitality sharing platform, has been available in over 191 countries. However, among those countries, the penetration rates vary significantly. Beijing and New York, as the two most representative cities of the two largest economies in the world, are selected as examples. In 2019, the total number of Airbnb listings in New York $(48,864)$ was about two times more than the number in Beijing $(25,921)$. Since the population of Beijing (21.8 million) is significantly larger than the population in New York City (8.4 million). Airbnb shows a much higher penetration in New York than in Beijing.

Existing studies have proven that culture plays a vital role in technology acceptance and diffusion problems (e.g., Calhoun et al., 2002; Jones et al., 2006; Qi \& Chau, 2015). Online hospitality platforms are commonly perceived as a group of emerging disruptive and innovative technologies due to their ability to directly connect ordinal people to hospitality sharing (Guttentag, 2015; Guttentag \& Smith, 2017; O'Regan \& Choe, 2017). However, there is a lack of research that has studied the possible influence of cultural values on online sharing hospitality platform acceptance problems.

Moreover, facilitating trust among strangers is always a key challenge for all types of sharing economy platforms because providers of goods and services are exposed to potential user opportunism (Horton \& Zeckhauser, 2016). Although trust has been repeatedly identified as the most critical driver of the success of the sharing economy (e.g., Botsman, 2012; Ufford, 2015), studies into trust in the sharing economy are still limited, especially trust in platforms (Huurne et al., 2017).

Although there are many studies that have investigated the effects of cultural values and trust on technology acceptance problems, and hospitality sharing industry has recently attracted much 
attention, a study on culture and trust in this context is currently lacking. Thus, the current study addresses the research question: How do culture and trust affect people's intention to adopt online sharing hospitality platforms? The research objectives are threefold: (1) to investigate the influence of culture in online sharing hospitality platform acceptance, (2) to examine the effects of trust in adopting online sharing hospitality platforms and, (3) to study the interaction effects of cultural values and trust in this context.

The rest of the paper is organized as follows. The authors first review the relevant literature and theories. Next, hypothesis development will be presented, followed by an overview of the research model. Then the research method and analysis results will be introduced. Finally, the contributions, limitations, and future directions will be presented.

\section{LITERATURE REVIEW}

In this section, the authors comprehensively review the existing literature on the topics related to this paper, including the sharing economy, national culture, technology acceptance, and the trust. The authors identify and highlight the research gaps by integrating the relevant studies.

Across a wide variety of studies and meta-analyses (Hall, 1989; Kroeber,1952; Straub et al., 2002), Hofstede's theory is one of the most popular. Hofstede (1980) defined culture as "the collective programming of the mind which distinguishes the members of one human group from another" (p.260). Hofstede's four cultural dimensions; power distance, individualism/collectivism, masculinity/ femininity, and uncertainty avoidance have been used to study the effects of national culture on various behavioral and economic contexts (Sondergaard, 1994). Later on, Hofstede and Bond (1988) developed a fifth dimension, long-term orientation. Table 1 summarizes the five dimensions and their definitions. Srite and Karahanna (2006) studied the moderating role of espoused individual-level cultural values in technology acceptance using Hofstede's first four cultural dimensions (Hofstede, 1983). They developed individual-level scales for these four dimensions based on existing measures of culture (Dorfman \& Howell, 1988; Hofstede, 1983), addressing concerns with country-level assessments of cultural values.

Examining cultural influences on technology acceptance and diffusion has always been a popular topic (Chu et al., 2019; Leidner \& Kayworth, 2006; Sia et al., 2009). To investigate the cultural effects, researchers commonly integrate the cultural dimensions into popular technology acceptance theories, such as the theory of reasoned action (TRA) (Fishbein \& Ajzen, 1977), the theory of planned behavior (TPB) (Ajzen, 1985), the technology acceptance model (TAM) (Davis, 1989), and the unified theory of acceptance and use of technology (UTAUT) (Venkatesh et al., 2003) (e.g., Al-Gahtani, 2003; Reinecke \& Bernstein, 2013; Zhou et al., 2015). For example, to examine the role and the influence of culture, Venkatesh and Zhang (2010) examined the UTAUT across two different cultural contexts: the USA and China. Additionally, Hoehle et al. (2015) found support for the role

Table 1. Five Dimensions of Cultural Values

\begin{tabular}{|c|c|}
\hline Dimensions & Definitions \\
\hline Power Distance & $\begin{array}{c}\text { The extent to which the less powerful people expect and accept that power is distributed } \\
\text { unequally. }\end{array}$ \\
\hline Individualism/Collectivism & The extent to which people prefer to act as individuals or as members of groups. \\
\hline Masculinity/Femininity & The extent to which people believe whether social gender roles are distinct \\
\hline Uncertainty Avoidance & The extent to which people feel threatened by uncertain or unknown situations \\
\hline Long-Term Orientation & $\begin{array}{c}\text { The extent to which people foster virtue oriented views towards the current of future } \\
\text { rewards. }\end{array}$ \\
\hline
\end{tabular}


of espoused national cultural values in moderating the impact of mobile social media application usability on continued intention to use.

Among different theories, the technology acceptance model (TAM) has been one of the most widely adopted models for understanding the intention to use technology (Davis, 1989). TAM was initially based on the theory of reasoned action (TRA) (Fishbein \& Ajzen, 1977). As Figure 1 shows, TAM suggests that perceived ease of use (PEOU) influences perceived usefulness (PU) and that both variables affect behavioral intention to accept a specific technology, which ultimately influences usage. PEOU refers to the degree to which a person believes that using a particular technology would be free of effort. PU refers to the degree to which a person believes that using a particular technology would enhance his/her performance.

TAM is also a popular theory to apply when researchers study the cultural effects on technology acceptance problems (e.g., Haapaniemi \& Makinen, 2009; Rose \& Straub, 1998; Straub, Keil et al., 1997). For example, Srite and Karahanna integrated espoused national cultural values into an extended TAM model as moderators. They found that some cultural dimensions do have a moderating effect on the relationships in the TAM model (Srite \& Karahanna, 2006). Later, to study the acceptance of a personal web portal in the US and China, researchers incorporated national culture values into the TAM model. The results stress the importance of including the national cultural dimensions in studies of technology acceptance and measuring cultural values at the individual level (Li et al., 2009).

The popularity of the sharing economy has drawn scholars from a large number of disparate fields and disciplines into this emerging research area in recent years (e.g., Lin et al., 2017). Several factors have been identified in motivating consumers to participate in the sharing economy, including sustainability, enjoyment, reputation, and economic benefits (e.g., Hamari et al., 2016; Kim et al., 2015). Although it is possible to infer how digital platforms benefit various parties, few of the existing studies on the sharing economy problematizes the technology itself in a sociotechnical perspective or the unique interactions with social norms and cultures (Sutherland \& Jarrahi, 2018). To fill the research gap, in this paper, the authors investigate the acceptance problem of online sharing hospitality platforms as well as the possible moderating effects of national cultural values.

Trust is commonly defined as an individual's willingness to depend on another party because of the characteristics of the other party (Rousseau et al., 1998). To understand trust in an e-commerce environment, McKnight and Chervany (2001) proposed a trust model for e-commerce. In their model, they distinguished disposition to trust, institution-based trust, trusting beliefs, trusting intentions, and trust related behaviors. Previously, trust was usually defined and examined in terms of trust in people (McKnight et al., 2011), such as trust in Internet vendors (e.g., Gefen et al., 2003).

Although trust in people, organizations, or human surrogates are critical, trust in an IT artifact itself also plays an essential role in shaping IT-based beliefs and behavior. Rooted in the previous trust in people research (Mayer et al., 1995; McKnight \& Chervany, 2001; McKnight et al., 1998), the authors operationalize trust in technology constructs as components of three sets of concepts:

Figure 1. TAM model

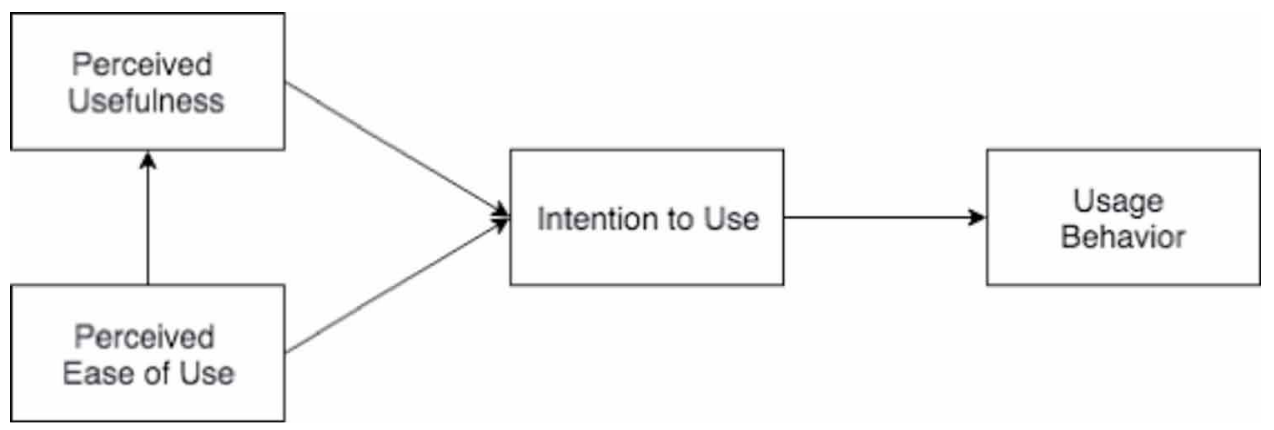




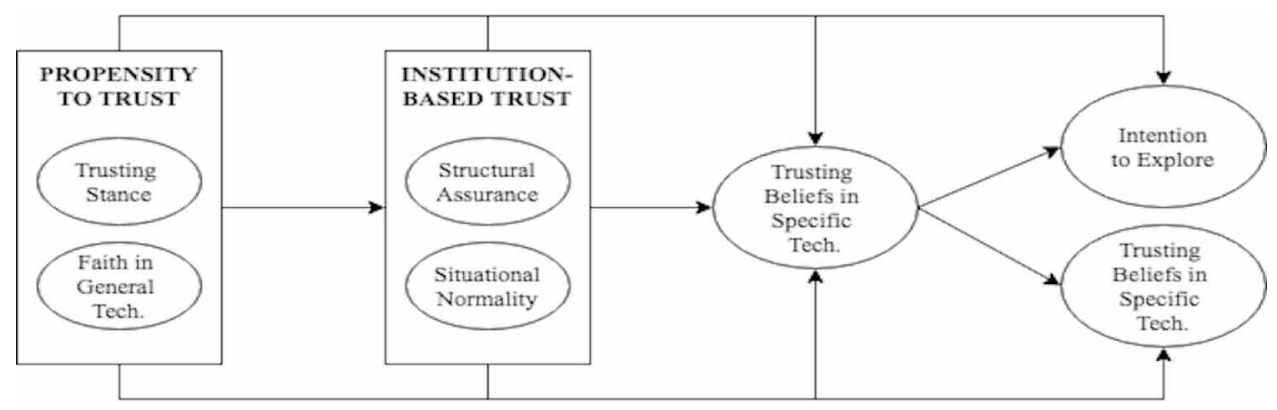

(a) propensity to trust general technology, (b) institution-based trust in technology, and (c) trust in a specific technology (McKnight et al., 2011). The propensity to trust refers to individuals' beliefs about Information technologies in general. Institution-based trust refers to beliefs about a specific class of technologies within a context, such as trust in spreadsheet products. Trust in a specific technology reflects beliefs about the favorable attributes of a specific technology, such as trust in MS Excel. According to their model, the propensity to trust directly influences institution-based trust, and the institution-based trust shapes trust in a specific technology, which will, as a result, affect behavioral intentions. Furthermore, the authors believe that trust in a specific technology should fully mediate more general constructs' influence on behavior (McKnight et al., 2011). Figure 2 shows the model of trust in technology theory.

Trust is generally recognized as the most critical driver to the success of the sharing economy. Thus, many researchers have investigated trust in the sharing economy (Abramova et al., 2015; Liu et al., 2016; Mittendorf, 2016). In the study of the role of personal photos on Airbnb, the researchers suggest that guests rely more on the host's photo as communicating trustworthiness compared with review scores. Sellers who have a personal photo were perceived as more trustworthy and had a higher probability of being booked (Ert et al., 2016). To explore the role of social trust at the country level to assess the size of the sharing economy, Bergh and Funcke (2016) built regression models. They found that social trust was a significant variable in predicting the size of the sharing economy.

However, research into trust in the sharing economy is still lacking, especially relating to trust in digital platforms (Huurne et al., 2017). Moreover, according to the best of the authors' knowledge, no study has attempted to explore the possible moderating effects of trust and cultural values on sharing economy platform acceptance. Thus, to fill the above gap, the authors examine the influences of trust, and the possible interaction effects with cultural values on the acceptance of online sharing hospitality platforms in this paper.

In sum, the authors propose a model that can be used to test the possible influence of espoused national cultural values, trust in technology, as well as the interactions between them on the acceptance of online sharing hospitality platforms.

\section{Hypotheses and Model Development}

The researchers extend their model of online sharing hospitality platforms acceptance from the technology acceptance model by adding three independent variables (subjective norms, trustsituational normality, and trust- structural assurance) on behavioral intention to use, one independent variable (espoused individualism/collectivism) on both perceived usefulness and perceived ease of use, and four moderators (espoused power distance; espoused individualism/collectivism; espoused masculinity/femininity; and espoused uncertainty avoidance). Figure 3 shows the model.

The research target is online sharing hospitality platforms, which refer to a class of digital platforms within the hospitality sharing context. The reasons are twofold. First, this study is a cross- 
country study, which conducted in both China and the US. The popularity of diverse online sharing hospitality platforms may be different in these two countries. Thus, it will be easy to detect bias if the researchers choose a specific platform for the participants in these two countries. Second, instead of investigating a specific platform, the researchers aim to gain a more holistic understanding of digital platform acceptance in the hospitality sharing industry.

\section{TAM Model Determinants}

Based on the technology acceptance model (TAM) (Davis, 1989), the researchers propose that the intention to use an online hospitality platform is determined by perceived ease of use and perceived usefulness. When users of online sharing hospitality platforms believe that technology requires little effort to use, they will be more likely to form positive intentions to use the platforms. Users will also be more likely to have positive intentions when they believe that the platforms can provide more and better online services. Furthermore, if users find an online sharing hospitality platform is easy to use, they are more likely to believe it is useful. Therefore, the authors proposed the following hypotheses:

H1: Perceived usefulness positively affects users' intention to use an online sharing hospitality platform.

H2a: Perceived ease of use positively affects users' intention to use an online sharing hospitality platform.

H2b: Perceived ease of use positively affects users' perceived usefulness of and online sharing hospitality platform.

Figure 3. Research Model

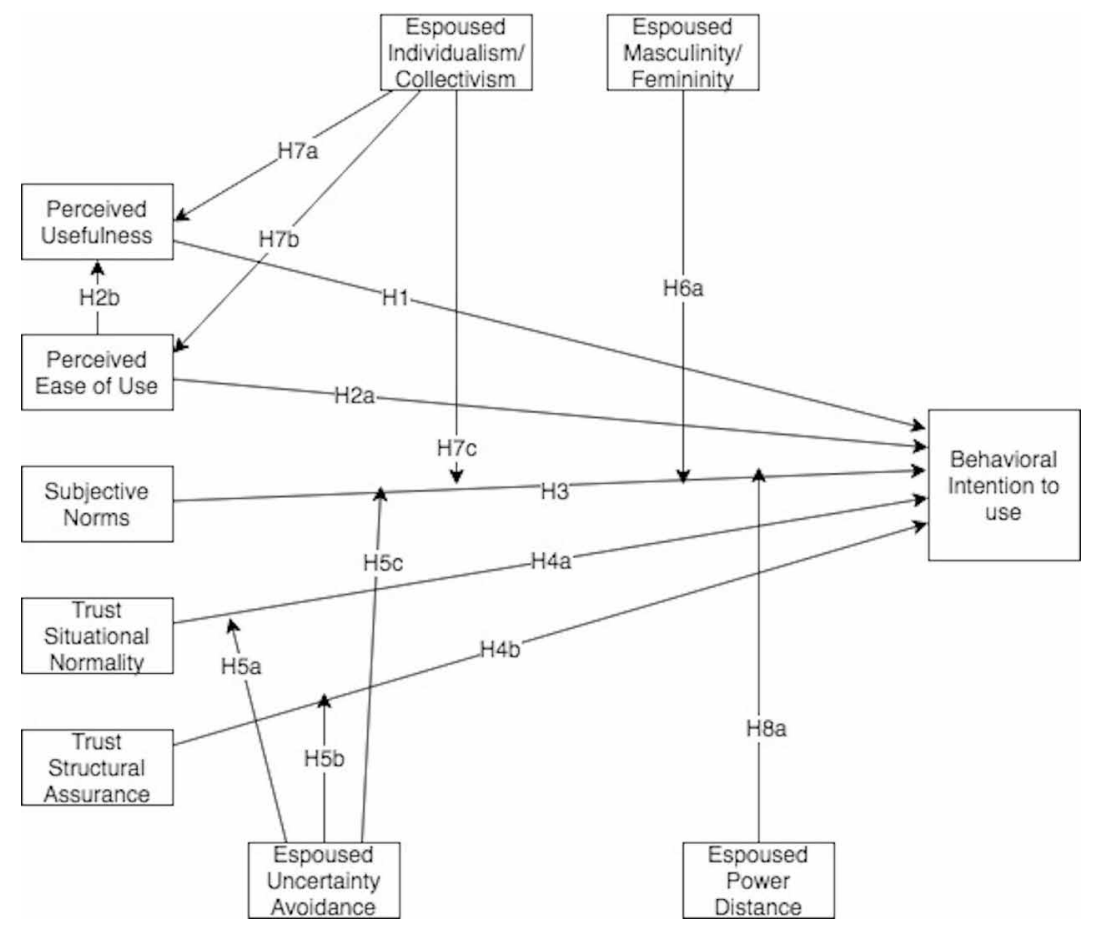




\section{Subjective Norms}

Previous research suggested that the person's perception of whether important referents think he or she should use the technology is also crucial to technology adoption intentions (Fishbein \& Ajzen, 1977). Therefore, other than perceived ease of use and perceived usefulness, the authors also include social influence from the TRA model (Firshbein \& Ajzen, 1977). Subjective norms are defined as perceptions that relevant referent groups think one should or should not perform the behavior in question. When adopting an online sharing hospitality platform such as Airbnb, users may value the opinions from their direct referents such as relatives, peers, and friends. If they find that most of the referents want them to adopt the sharing hospitality platform, they will tend to adopt it. Therefore, the authors propose that:

H3: Subjective norms positively affect users' intention to use an online sharing hospitality platform.

\section{Trust}

The theory, trust in technology (McKnight et al., 2011), is developed from multiple trust theories. Unlike previous theories that mainly focus on the trust in other people, the trust in technology theory suggests that trust in the information technology plays a critical role in shaping IT-related beliefs and behaviors. According to the theory, trust in technology has three sets of concepts: a) propensity to trust general technology b) institution-based trust in technology, and c) trust in a specific technology. The trust in a specific technology should fully mediate more general constructs' influence on behavior (McKnight et al., 2011).

In this research, the authors adopt two trust constructs from the area of institution-based trust. On the one hand, the research target is the online sharing hospitality platforms, which is recognized as a class of technologies. According to the theory, institution-based trust refers to beliefs about a specific class of technologies within a context. The authors believe the institution-based trust fits the level of their research target the best.

On the other hand, according to the existing literature, the antecedents and consequences of other types of trust, such as trust in people, trust in organizations, and trust in e-word-of-mouth, do not differ much in the sharing economy context from the consumer-to-consumer e-commerce contexts. However, this rule does not apply to the institution-based trust since it is the institutional difference that distinguishes transactions in the sharing economy from traditional transactions (Huurne et al., 2017, p.495). There is no existing study that has tried to explain the effects of institution-based trust in the sharing economy context. Thus, the researchers hope to explore the influence of institutionbased trust on individuals' acceptance of online sharing hospitality platforms.

The institution-based trust consists of two constructs: situational normality and structural assurance. Situational normality in trust in the context of technology theory reflects the belief that using a specific class of technologies in a new way is normal and comfortable within a specific setting. For example, one may perceive using online sharing hospitality platforms to look for accommodations is a normal activity and feel comfortable using online sharing hospitality platforms in general, and this may result in the intention to use online sharing hospitality platforms.

Structural assurance refers to the infrastructure supporting technology use. It presupposes the belief that adequate support exists. This support can be legal, contractual, or physical to ensure the successful use of IT. For example, the appropriate reputation system and legal structures may increase one's confidence in the platforms, thereby increasing the intention to adopt the platforms.

Thus:

H4a: Trust-situational normality positively affects users' intention to use an online sharing hospitality platform.

H4b: Trust-structural assurance positively affects users' intention to use an online sharing hospitality platform. 


\section{Uncertainty Avoidance}

In strong uncertainty avoidance (UA) cultures, individuals feel threatened by unknown or uncertain situations. This feeling is expressed through increased nervous stress, and anxiety, and the need for predictability through formal rules and structure in organizations, institutions, and relationships (Hofstede, 1983). Previous studies have found that UA plays a significant role in determining how people will accept information technologies (Leidner \& Kayworth, 2006).

Trust is closely related to uncertainty avoidance since it is vital in situations of risk and uncertainty (McKnight \& Chervany, 2001). Nevertheless, they are different, essentially. Trust is a belief that can be cultivated from the attributes of the trustee, such as ability, benevolence, and integrity. It means individuals' trust beliefs can form and change based on several factors. However, uncertainty avoidance, as one of the cultural values which are acquired early on in life through lifestyle-altering experiences, is relatively stable (Karahanna et al., 2005). Once a value is learned, it is integrated into an organized system of values.

In other words, the formation process of trust is rational and dynamic. For example, if an online platform is adopted widely and has adequate support, one may perceive it as trustworthy, and as a result, be more willing to accept it. On the other hand, the use of cultural values like uncertainty avoidance is irrational and subconscious. For people high in uncertainty avoidance, even though they believe an online platform is trustworthy, as long as the adoption will cause uncertainty and ambiguity, they will feel uncomfortable and refuse to change subconsciously (Hofstede, 2015; Hofstede, 2018). Therefore, the authors believe that individuals who espouse high levels of uncertainty avoidance value will mitigate the effects of trust on online sharing hospitality platforms acceptance. Thus, the researchers propose the following hypotheses:

H5a: The relationship between trust-situational normality and behavioral intention to use is moderated by the espoused national cultural value of espoused uncertainty avoidance such that the relationship is weaker for individuals with higher espoused uncertainty avoidance values.

H5b: The relationship between trust-structural assurance and behavioral intention to use is moderated by the espoused national cultural value of espoused uncertainty avoidance such that the relationship is weaker for individuals with higher espoused uncertainty avoidance values.

Individuals with high uncertainty avoidance have a low tolerance for ambiguity and risk. When ambiguous situations cannot be avoided, high uncertainty avoidance individuals will search for simple rules or references to reduce this ambiguity (Marcus \& Gould, 2000). Subjective norms may, through informational and normative influences, reduce uncertainty as to whether the use of a technique is appropriate (Evaristo \& Karahanna, 1998). Uncertainty can be reduced through information from relatives and friends of individuals to inform them of their personal experiences and perceptions of the system, or when they can observe peers using the system (Srite \& Karahanna, 2006).

In general, high espoused uncertainty avoidance individuals are believed to be more likely to follow their normative beliefs when adopting a new technology (e.g., Dinev et al., 2009; McCoy et al., 2005; Singh, 2006). For example, to examine the role of espoused national cultural values in technology acceptance, Srite and Karahanna (2006) conducted two studies, one on personal computers, the other on personal digital assistants. Both studies found that the espoused uncertainty avoidance had a significant moderating effect on the relationship between subjective norms and behavioral intention to use, such that this relationship was stronger for individuals with high levels of espoused uncertainty avoidance. Because online sharing hospitality platforms are a group of innovative technologies, the authors believe the acceptance behavior should follow the existing findings. Thus, the authors propose: 
H5c: The relationship between subjective norms and behavioral intention to use is moderated by the national cultural value of espoused uncertainty avoidance such that the relationship is stronger for individuals with higher espoused uncertainty avoidance cultural values.

\section{Masculinity/Femininity}

Masculinity/femininity is a measure of psychological gender. It refers to whether a society or an individual espouses masculine values or feminine values (Hofstede, 1983). People who espouse high levels of masculine values place a greater emphasis on goals, assertiveness, and material success. On the contrary, people espouse to feminine culture values tend to be more concerned about maintaining personal relationships and interpersonal harmony.

As a group of innovative sociotechnical systems in the context of hospitality sharing, people who espouse high levels of feminine cultural values should find that online sharing hospitality platforms to be more attractive if their relevant referent groups (e.g., parents, friends, and colleagues) recommend them to use one of the online sharing hospitality platforms when they search for accommodations. That is because they are more likely to conform to social pressures than those who espouse high levels of masculine values (Srite, \& Karahanna, 2006). Several studies have found that masculinity/ femininity, may influence the strength of the relationship between social influence and technology acceptance (Dinev et al., 2009; McCoy et al., 2005; Srite, \& Karahanna, 2006).

Therefore, the researchers believe that individuals who espouse higher levels of feminine cultural values will be influenced more by the recommendations from their salient referents towards the online sharing hospitality platforms acceptance than individuals who espouse higher levels of masculine values. Thus, they propose the following hypothesis:

H6a: The relationship between subjective norms and behavioral intention to use is moderated by the national cultural value of espoused masculinity/femininity such that the relationship is stronger for individuals with espoused feminine cultural values.

\section{Individualism/ Collectivism}

Hofstede indicated that individualism stresses goals in which the person is an active agent versus those in which he or she is dependent on the organization (Hofstede, 1983). In individualistic cultures, social behavior is primarily guided by personal goals, while in collectivistic cultures, the goals of the collective have a dominant influence in shaping behavior (Triandis, 1989).

Previous research provides evidence that individualism/collectivism may affect users' perception of the usefulness of the technology. Veiga et al. (2001) found that technologies that can enhance group performance and connections are more useful to collectivists. An online sharing hospitality platform can connect people and provide further offline interaction possibilities, which may be more appealing to collectivists.

Furthermore, Singh et al. (2003) proposed that some web elements, such as community relations and links to local web sites, can be treated as collectivist web site features. Online sharing hospitality platforms commonly have features to connect hosts and guests; such as links to hosts' social media accounts. Therefore, the researchers propose that:

H7a: The higher the espoused collectivistic value, the higher the users' perceived usefulness of online hospitality platforms.

Individualism/collectivism may also influence users' beliefs regarding the ease of use of technology. As Nakata and Sivakumar (1996) mentioned, people in a culture with high individualism are more self-confident about generating possibilities and overcoming obstacles. Furthermore, individualists tend to be more confident in adopting new technologies (Thatcher et al., 2003) and 
perceive less difficulty in the adoption process ( $\mathrm{Li}$ et al., 2009). Existing studies found that users with high individualism are more likely to find technology easy to use (e.g., Lee et al., 2007; Li et al., 2009). Thus:

H7b: The higher the espoused individualistic value, the higher the users' perceived ease of use of online sharing hospitality platforms.

People who espouse individualistic cultural values are also less concerned about the opinions of others in their social environment (Srite \& Karahanna, 2006). On the contrary, people who espouse high collectivist cultural values tend to put more emphasis on the group they belong to (Singh et al., 2003) and are more influenced by their group referents. In terms of adopting new technology, users with high collectivism will think more about how their referents may regard or be affected by their adoption behaviors (Srite \& Karahanna, 2006). Several studies have proved that social influence has a stronger effect on technology acceptance with a more collectivist culture (Dinev et al., 2009; Pavlou $\&$ Chai, 2002). Therefore, the researchers propose that:

H7c: The relationship between subjective norms and behavioral intention to use is moderated by the national cultural value of espoused individualism/collectivism such that the relationship is stronger for individuals with espoused collectivistic cultural values.

\section{Power Distance}

Power distance refers to the degree to which status inequality is accepted as normal in a given culture (Hofstede, 1983). The authors suggest that espoused power distance will moderate the relationship between subjective norms and intended behavior. Previous research has found support that power distance will moderate the effect of social influence on behavioral intention in a technology acceptance context (e.g., Dinev et al., 2009; McCoy et al., 2005; Srite \& Karahanna, 2006).

Individuals with high espoused power distance cultural values will be more likely to comply with their superior's opinions (Hofstede, 1998). This compliance is due to individuals' willingness to be accepted by their superiors or other important referents such as parents and professors. (Kelman, 1958). In accepting online sharing hospitality platforms, individuals with high espoused power distance values would care more about their referents' opinions towards the platforms. Therefore, the researchers propose the following hypothesis.

H8a: The relationship between subjective norms and behavioral intention to use is moderated by the national cultural value of espoused power distance such that the relationship is stronger for individuals with higher espoused power distance cultural values.

\section{Control Variables}

Based on previous research, and the authors' judgment, the authors include four control variables in the model: age (Venkatesh et al., 2003), gender (Venkatesh \& Morris, 2000), experience (Li et al., 2009) and nationality.

\section{Research Method}

The researchers conducted an online survey in China and in the US. The researchers developed the measurement scales mostly from prior studies. Each item was measured using a 7-point Likert-type scale $(1=$ strongly disagree, $7=$ strongly agree). The scales for perceived usefulness and perceived ease of use were adapted from the well-established scales of Davis (1989) and other related works (Pavlou \& Gefen, 2004; Venkatesh et al., 2012; Srite \& Karahanna, 2006). The scales for behavior 
intention to use were measured using scales adapted from Venkatesh et al. (2012). Subjective norms were formed separately by following four referent groups: relatives, friends, peers, and classmates/ colleagues. Because subjects' beliefs about the referent groups' opinions would not necessarily correlate with each other, these four items were treated as formative measures of subjective norms (Srite \& Karahanna, 2006). The scales for the cultural dimensions were based on previous culture related studies (Dorfman \& Howell, 1988; Hofstede, 1983; McCoy et al., 2005; Srite \& Karahanna, 2006).

The scales of the two trust constructs were developed from the trust in technology theory (McKnight et al., 2011). Initially, the researchers developed two constructs for situational normality based on the characteristics of hospitality sharing activities. The researchers believe that the two different situations are unique in the hospitality sharing context. The first situation is that people pay to share a living space with others, potentially including other strangers and/or the owners of the residence, and the second situation is that people pay to have a private space to themselves. Thus, the researchers divided the situational normality trust into two constructs and measured them with two separate sets of scales. However, the confirmatory factor analysis results showed that the items in the two constructs loaded together well within the minimum 0.698 loading score. The researchers believe that is because these two situations reflect the same situation essentially. So in the data analysis, the researchers combined the two constructs to a single construct (Situation Normality) by loading all items of two constructs into one construct when they built the structural equation model. Table 5 in Appendix A shows all the items used in the study.

According to Hofstede's country scores, some of the cultural values in these two countries are significantly different. Therefore, the authors believe that combining samples from the US and China will provide enough cultural variance. Before conducting the study in China, the surveys were translated into Chinese by one researcher, and then translated back by another translator. Both translators were native Chinese speakers. The back-translated surveys were consistent with the original English version.

At the beginning of the questionnaire, a paragraph was provided to introduce the concept of online sharing hospitality platforms and to help the unexperienced participants to gain a basic understanding. Then, several demographic questions were displayed. All the other questions for the primary research constructs were displayed randomly. Initially, the researchers received 498 responses. After eliminating the incomplete responses, the number in sample was 312. Then the researchers remove the responses with short duration to guarantee the quality of the responses. The final sample size was 239 , including 132 from the US respondents and 107 from China. The demographic information is summarized in Table 2. Table 6 in Appendix B reports the descriptive statistics of the observed variables.

Table 2 shows that the percentage of the US respondents who have experience in online sharing hospitality platforms is higher than Chinese respondents, which is consistent with the pattern the

Table 2. Demographic Information

\begin{tabular}{|c|c|c|c|}
\hline & US & China & Total \\
\hline Sample Size & 132 & 107 & 239 \\
\hline Age-Mean (SD) & $21.32(4.77)$ & $21.84(5.20)$ & $21.55(4.96)$ \\
\hline \multicolumn{2}{|c|}{ Gender } \\
\hline Female & 44 & 82 & $126(52.72 \%)$ \\
\hline Male & 88 & 25 & $113(47.28 \%)$ \\
\hline No Experience & Experience with Online Sharing Hospitality Platforms \\
\hline Have Experience & $79(59.85 \%)$ & $75(70.10 \%)$ & $154(64.44 \%)$ \\
\hline
\end{tabular}


authors observed for Airbnb in the introduction section. Furthermore, the relatively low percentage of respondents, in both countries, who have experience suggests that online sharing hospitality platforms are in the initial phase of development and have excellent growth potential. The comparison to the hotel industry can reveal this phenomenon. For example, there were over 115,530 hotel rooms in New York City in 2017 (New York City Department of City Planning, 2017). Whereas, the number of Airbnb listings was 48,864 in 2019.

\section{Data Analysis and Results}

An R package, Lavaan, was used for data analysis to allow for structural equation modeling developed by Rosseel (2012). Both reflective and formative constructs were measured, and moderating effects were included in the model (Chin et al., 2003). The structural regression model was run with both the US and China samples combined.

\section{Reliability and Validity Check}

Lavaan (Rosseel, 2012), was also used to check the internal consistency and discriminant validity of the constructs in the context of the research method. To check the reliability, the authors calculated the composite reliabilities. The shaded column of Table 3 contains these values. All values exceed the 0.7 recommended level (Nunnally, 1994) except Power Distance and Individualism/Collectivism. Since the composite reliabilities achieved the acceptable level 0.6 (Fornell \& Larcker, 1981), the researchers decided to keep them. Table 4 contains the confirmatory factor analysis results for the final items. As can be observed from Table 4, most of the items exceed, or are at least close enough to, the 0.7 loading criterion as suggested by Fornell and Larcker (1981). Since the exceptions were all statistically significant as can be seen from Table 4, it was decided to retain them in the analysis.

In order to assess discriminant validity, the researchers calculated the average variance extracted (AVE). As Chin recommended, the square root of AVE (leading diagonal in Table 3) should be larger than the inter-construct correlations. As can be seen, most of the correlations are less than the square root of AVE (Chin, 1998). Overall, these results suggest that the scales exhibit adequate psychometric properties.

\section{Structural Model}

Having confirmed construct validity, the researchers ran a structural model with all hypothesized relationships. All constructs except for subjective norms were modeled as reflective. As suggested by previous studies, the subjective norms' referent groups may have diverse opinions towards specific behaviors (Karahanna et al., 2005; Srite, \& Karahanna, 2006), and they are not necessarily correlated with each other. Thus, the authors modeled subjective norms as a formative construct.

Adapting the approach from Chin et al. (2003), moderating effects were modeled by crossproducts. The cross-products were created by multiplying indicators of each of the interacting constructs. These cross-products were then used as indicators in the interaction term. Weights for the formative indicators were all significant at least at the 0.05 significance level.

Figure 4 summarizes the full structural model results, including path coefficients, significance, and R-squared values. The significance level threshold was set to be 0.05 , which means the paths with the p-value greater than 0.05 will all considered to be insignificant. The insignificant paths are labeled as 'n.s.' in Figure 4. The model can explain a 78.6 percent variation in behavioral intention to use, a 97.9 percent variation in perceived usefulness and a 47.7 percent variation in perceived ease of use.

The relationships inherent from the TAM model were all significant at least at the 0.05 level. That means the hypotheses H1, H2a, and H2b were all supported. Subjective Norms (SN) had a significant positive relationship with intentions. Thus H3 was supported.

Two constructs relative to trust: trust-situational normality (TSN) and trust-structural assurance (TSA) both had a significant positive relationship with behavioral intention. Thus H4a and H4b were supported. As hypothesized, the espoused Uncertainty Avoidance (UA) values moderated the 
Table 3. Correlations and Square Roots of AVEs

\begin{tabular}{|c|c|c|c|c|c|c|c|c|c|c|c|}
\hline & CR & PU & PEOU & SN & TSN & TSA & IC & MF & UA & PD & BI \\
\hline PU & $\mathbf{0 . 7 7}$ & $\mathbf{0 . 6 7}$ & & & & & & & & & \\
\hline PEOU & $\mathbf{0 . 8 3}$ & 0.97 & $\mathbf{0 . 7 4}$ & & & & & & & & \\
\hline SN & NA & 0.83 & 0.72 & $\mathbf{0 . 6 5}$ & & & & & & & \\
\hline TSN & $\mathbf{0 . 9 0}$ & 0.63 & 0.61 & 0.68 & $\mathbf{0 . 7 3}$ & & & & & & \\
\hline TSA & $\mathbf{0 . 7 9}$ & 0.95 & 0.83 & 0.72 & 0.50 & $\mathbf{0 . 7 0}$ & & & & & \\
\hline IC & $\mathbf{0 . 6 2}$ & 0.58 & 0.44 & 0.44 & 0.36 & 0.51 & $\mathbf{0 . 6 0}$ & & & & \\
\hline MF & $\mathbf{0 . 8 0}$ & 0.46 & 0.31 & 0.40 & 0.29 & 0.42 & 0.55 & $\mathbf{0 . 7 5}$ & & & \\
\hline UA & $\mathbf{0 . 7 1}$ & 0.70 & 0.67 & 0.38 & 0.35 & 0.77 & 0.44 & 0.18 & $\mathbf{0 . 7 5}$ & & \\
\hline PD & $\mathbf{0 . 6 0}$ & 0.42 & 0.34 & 0.48 & 0.47 & 0.39 & 0.56 & 0.77 & 0.17 & $\mathbf{0 . 6 5}$ & \\
\hline BI & $\mathbf{0 . 8 1}$ & 0.85 & 0.79 & 0.84 & 0.57 & 0.76 & 0.49 & 0.43 & 0.45 & 0.43 & $\mathbf{0 . 8 2}$ \\
\hline
\end{tabular}

PD: power distance, IC: individualism/collectivism, MF: masculinity/femininity, UA: uncertainty avoidance, PU: perceived usefulness, PEOU: perceived ease of use, SN: Subjective Norms, TSN: Trust Situational Normality; TSA: Trust Structural Assurance, BI: Behavioral Intention

* Diagonal elements in the correlation of constructs matrix are the square roots of the average variance extracted.

relationships between two constructs of trust (TSN and TSA) and behavioral intention providing support for $\mathrm{H} 5 \mathrm{a}$ and $\mathrm{H} 5 \mathrm{~b}$. The moderating effect of UA on the relationship between $\mathrm{SN}$ and behavioral intentions (BI) was significant as hypothesized. Thus H5c was supported.

The moderating effect of the espoused masculinity/femininity (MF) on the relationship between $\mathrm{SN}$ and BI was not significant. Thus H6a was not supported. The significant positive relationship between the espoused individualism/collectivism (IC) and perceived usefulness (PU) means the higher a person espoused collectivistic values are, the higher perceived usefulness will be, which provides support for H7a. The moderating effect of IC on the relationship between SN and BI was not significant. Thus H7c was not supported. The direct effect of IC on PEOU was significant but in the opposite direction as hypothesized (H7b). The hypothesized moderating effects of the espoused power distance (PD) on the relationship between SN and BI was not significant. Thus H8a was not supported.

Two control variables were found to be significant in the final analysis. A significant negative relationship was found between age and BI. Nationality had a significant negative relationship on behavioral intentions. Chinese participants had more intentions to adopt to online hospitality platforms than did the US participants.

\section{Discussion}

In this paper, the authors studied the relationships between culture and technology adoption behavior. Specifically, the authors examined the effects of Hofstede's four cultural dimensions, as well as trust, on the user's intention to adopt an online sharing hospitality platform. The research model is extended from the Technology Acceptance Model (Davis, 1989). The proposed model contains moderating effects of cultural values as well as two constructs relevant to trust. The results show that some of the hypotheses are supported. In the following, the detailed discussion and explanation of these results will be included.

\section{Trust}

In this paper, the authors adapted the trust theory from McKnight et al. (2011). Given that the research target is online sharing hospitality platform, which is a unique class of technologies, thus the authors adapted institution-based trust in information technology from the trust in technology 
Table 4. Confirmatory Factor Analysis

\begin{tabular}{|c|c|c|c|c|}
\hline Latent Factor & Indicator & Beta & $\mathbf{Z}$ & p-value \\
\hline \multirow[t]{4}{*}{$\mathrm{PU}$} & PU1 & 0.649 & 11 & 0 \\
\hline & PU2 & 0.714 & 12.416 & 0 \\
\hline & PU3 & 0.678 & 11.607 & 0 \\
\hline & PU4 & 0.648 & 10.971 & 0 \\
\hline \multirow[t]{4}{*}{ PEOU } & PEOU1 & 0.741 & 12.891 & 0 \\
\hline & PEOU2 & 0.739 & 12.847 & 0 \\
\hline & PEOU3 & 0.804 & 14.497 & 0 \\
\hline & PEOU4 & 0.706 & 12.081 & 0 \\
\hline \multirow[t]{8}{*}{ TSN } & TSNI1 & 0.774 & 13.799 & 0 \\
\hline & TSNI2 & 0.718 & 12.419 & 0 \\
\hline & TSNI3 & 0.734 & 12.78 & 0 \\
\hline & TSNI4 & 0.768 & 13.633 & 0 \\
\hline & TSNII1 & 0.716 & 12.368 & 0 \\
\hline & TSNII2 & 0.706 & 12.125 & 0 \\
\hline & TSNII3 & 0.698 & 11.95 & 0 \\
\hline & TSNII4 & 0.703 & 12.063 & 0 \\
\hline \multirow[t]{4}{*}{ TSA } & TSA1 & 0.695 & 11.73 & 0 \\
\hline & TSA2 & 0.738 & 12.72 & 0 \\
\hline & TSA3 & 0.752 & 13.046 & 0 \\
\hline & TSA4 & 0.608 & 9.883 & 0 \\
\hline \multirow[t]{3}{*}{ IC } & IC1 & 0.523 & 7.206 & 0 \\
\hline & IC3 & 0.706 & 9.7 & 0 \\
\hline & IC4 & 0.529 & 7.308 & 0 \\
\hline \multirow[t]{3}{*}{ MF } & MF1 & 0.762 & 12.669 & 0 \\
\hline & MF2 & 0.708 & 11.532 & 0 \\
\hline & MF5 & 0.791 & 13.31 & 0 \\
\hline \multirow[t]{2}{*}{ UA } & UA1 & 0.669 & 10.411 & 0 \\
\hline & UA5 & 0.824 & 12.872 & 0 \\
\hline \multirow[t]{2}{*}{ PD } & PD1 & 0.73 & 10.208 & 0 \\
\hline & PD2 & 0.583 & 8.439 & 0 \\
\hline \multirow[t]{2}{*}{ BI } & BI1 & 0.839 & 14.954 & 0 \\
\hline & BI2 & 0.807 & 14.214 & 0 \\
\hline
\end{tabular}

theory. There are two constructs for institution-based trust, situational normality, and structural assurance. As McKnight et al. (2011) defined, situational normality refers to a belief that when a situation is viewed as normal and well-ordered, one can extend trust to something new in the situation and structural assurance refers to trust of the infrastructure supporting technology use. The authors initially separated situational normality into two sub-constructs since the authors assumed two distinct 


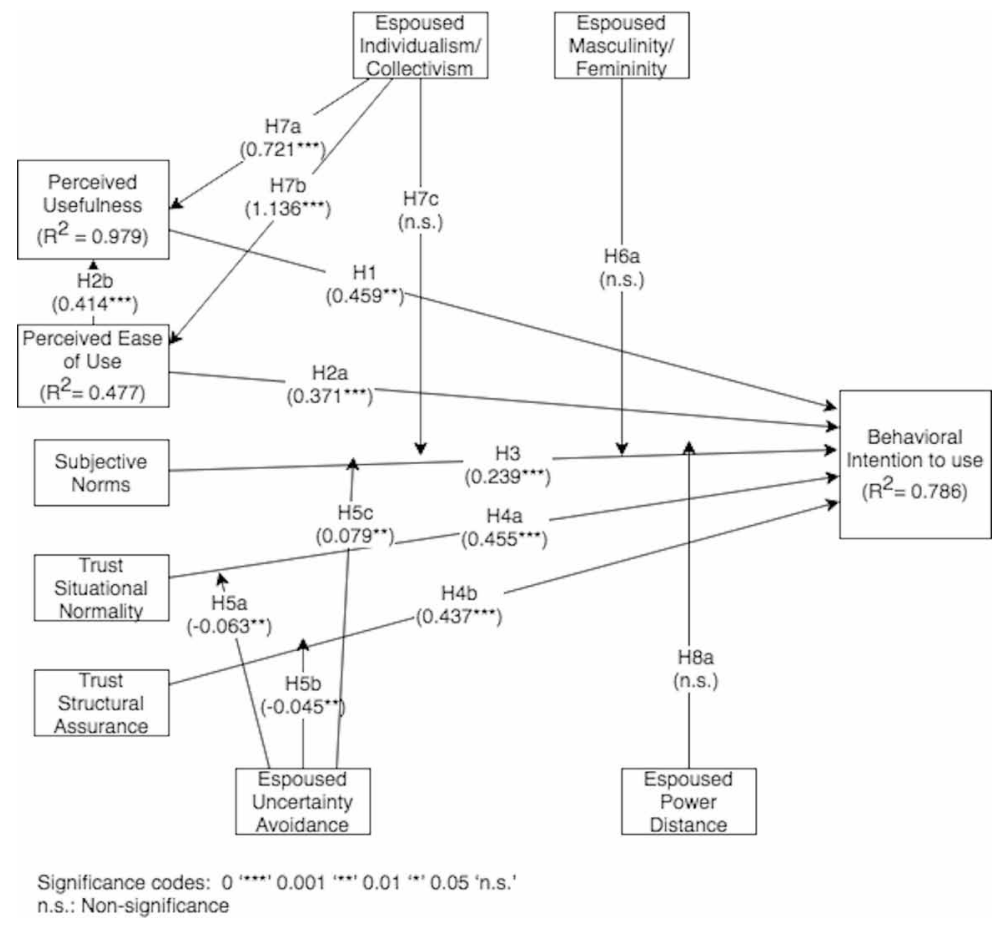

situations involved in the online hospitality platform phenomenon. However, the data analysis results indicated that the items of these two constructs were highly correlated. Thus the authors integrated the two sub-constructs for situational normality into one construct by merging all items of two subconstructs into a single construct.

As hypothesized, the authors found two significant positive relationships of situational normality and structural assurance on behavioral intentions. Unlike most of the other information technologies that only facilitate the online interactions between users, online sharing hospitality platforms can not only link people online but also connect users offline. Specifically, guests will share the living space with their hosts. Therefore, the users should not only trust the platforms' infrastructure supports (TSA) but also accept this situation (TSN). That is the reason why the authors find significant relationships for both of the two constructs related to trust.

\section{Uncertainty Avoidance}

Similar to trust, uncertainty avoidance should also play a more critical role in online sharing hospitality platforms adoption. In the current study, uncertainty avoidance was found to have a significant moderating effect on the relationship between subjective norms and behavioral intention to adopt, such that this relationship was stronger for individuals with a high level of espoused uncertainty avoidance. This indicates that individuals who espoused high uncertainty avoidance values are more likely to take the suggestions from their important referents.

Furthermore, the moderating effects of espoused uncertainty avoidance on the relationships between the two trust constructs and behavioral intentions were found to be significant, such that these relationships were weaker for individuals with higher levels of espoused uncertainty avoidance. People who espoused high uncertainty avoidance values tended to feel nervous, and also showed higher levels of stress and anxiety when they faced uncertain situations (Hofstede, 1983), and tended to resist change (Hofstede, 2018). So for people with high espoused uncertainty avoidance, even if 
they trust the technology and the situation, they will still feel nervous and refuse to adopt when they face a new and unknown phenomenon like online sharing hospitality platforms.

\section{Individualism/Collectivism}

As expected, individuals espoused to higher values of collectivism were found to perceive higher levels of the usefulness of online hospitality platforms. This was due to online hospitality platforms having many features related to community linkage, which are more appealing to collectivistic users. Moreover, the possibility to meet new friends and possible offline interactions may also attract those more collectivistic users.

The authors also proposed that more individualist users would find online sharing hospitality platforms to be easier to use. However, the results suggested the opposite way. A possible explanation is that the respondents for this study are almost all in their 20s (average age is 21.55). People in this age demographic grew up with information technologies, so most of them may not feel challenged to adopt any new technologies. Given the discussion above, the more collectivistic users may be more likely to be positive about online hospitality platforms and they may rate them higher than those individualistic users.

\section{Other Moderating Effects}

Other than the relationships discussed above, the authors also tested the moderating effects of the espoused masculinity/femininity(MF) and power distance(PD) in the online hospitality platforms adoption model. However, none of the remaining moderating effects were found to be significant in the current study.

In Srite and Karahanna's (2006) paper, they did not find that any of the moderating effects of MF and PD were significant in the study of personal digital assistant adoption neither. They suggested that cultural effects may differ with user experience and the nature of the technology. Thus, the study results confirm the lack of moderating effects of MF and PD, as reported in Srite and Karahanna's PDA study.

\section{Control Variables}

In this paper, the researchers tested several control variables and dropped insignificant control variables subsequently. Finally, two control variables were found significant on behavioral intentions: age and nationality.

\section{Contributions to Theory and Practice}

The findings from this study have significant contributions to theory. First, the sharing economy, as a popular topic, has been investigated from various perspectives by researchers from different domains. However, it still lacks research that investigates the sharing economy from a sociotechnical perspective (Sutherland \& Jarrahi, 2018). In this study, the authors develop a model to study the acceptance of online sharing hospitality platforms to reveal the mediating roles of digital platforms in the sharing economy. This research extended the current sharing economy studies and sheds light on a new direction for the development in this field.

Furthermore, trust has always been considered to play a vital role in technology adoption. Nevertheless, research into trust in the sharing economy is still lacking (Huurne et al., 2017), especially studies related to institution-based trust. However, it is the institutional difference that distinguishes transactions in the sharing economy from traditional transactions. In this study, the researchers adapted two institutional-based trust constructs from the trust in technology theory (McKnight et al., 2011), and investigated the influence of institution-based trust on the online sharing hospitality platforms acceptance. This study emphasized the necessity to study the influence of institution-based trust in the sharing economy, and enriches the existing trust in technology studies. 
Moreover, cultural values are perceived as essential factors to technology adoption. However, the role of culture in sharing economy platforms acceptance has not been adequately examined. In the current study, the authors examined the moderating effects of espoused cultural values in the online sharing hospitality platforms acceptance problem. The significant moderating effects of some espoused national cultural dimensions can enrich the cultural research and provide a holistic understanding of the sharing economy.

Last but not the least, the researchers identified significant moderating effects of some of the culture dimensions on behavioral intentions which is consistent with many other studies (e.g., Chang et al., 2015; Cyr et al., 2009; Dibbern et al., 2012; Hoehle et al., 2015; Zhou et al., 2015). Therefore, this paper further verified the moderating effects of culture on behavioral intentions to the acceptance of technologies.

The results of the study can also contribute to practice. First, the results show that two institutionbased trust constructs have significant positive effects on the behavioral intention to accept online sharing hospitality platforms. The significant relationships indicate that it is crucial for hospitality sharing companies to cultivate trust beliefs at the institution-based level. For example, the companies can leverage advertisements to deliver the benefits of sharing living space with others (situational normality) and emphasize the safety protection features of their digital platforms (structural assurance).

Furthermore, the results show that some espoused cultural values, especially espoused uncertainty avoidance, can influence individuals' intention to accept online sharing hospitality platforms. This result suggests that hospitality sharing companies should consider cultural differences when they develop strategies. For example, companies can provide their referents' usage history for individuals from high uncertainty avoidance cultures when they first visit their platform. Companies should also allocate more resources to build institution-based trust in high uncertainty avoidance culture since the high espoused uncertainty avoidance values can weaken the positive effects of institution-based trust.

\section{LIMITATIONS AND FUTURE DIRECTIONS}

In general, the percentage of participants who had experience with online sharing hospitality platforms were relatively low in the experiment. However, the low portion of experienced participants matched the current development status of the hospitality sharing industry. Although the researchers included an introduction to the concept of online sharing hospitality platforms at the beginning of the questionnaire to help the unexperienced participants gain a basic understanding of the process, the low percentage could still damage the reliability of the results. Future research can explicitly select participants who have prior experience with the digital platforms before conducting their study. If the percentage of experienced participants is high, researchers can consider investigating other dependent variables such as actual usage and intention to continue to use the platform.

Furthermore, the majority of the respondents in this study were students in their twenties. Thus, the average ages were relatively young. Future studies should consider utilizing participants from a broader range of ages as well as from actual working environments (which would have greater variation in age).

Although the technology acceptance model (TAM) is a popular theory to apply when researchers study the cultural effects on technology acceptance problems, there are many other popular theories of technology acceptance such as the theory of reasoned action (TRA) (Fishbein and Azjen, 1977) and the unified theory of acceptance and use of technology (UTAUT) (Venkatesh et al., 2003). In the future, researchers can adopt to other technology acceptance theories to investigate the digital platform acceptance problems in the context of the sharing economy.

In terms of cultural constructs, the researchers only used four constructs for culture from Hofstede's dimensions but did not consider the fifth dimension, long-/short-term orientation. Future research may examine the effects of that dimension. 
In the confirmatory factor analysis, some of the criteria did not achieve the optimal thresholds but only satisfied the basic requirements, which may affect the validity of the model. In the future, additional surveys may be conducted to verify the hypotheses further.

\section{CONCLUSION}

The objectives of this paper were to understand the role of espoused national cultural values as well as trust in technology acceptance in the context of online sharing hospitality platforms. The results suggest that institution-based trust plays a vital role in explaining the acceptance of online sharing hospitality platforms. Among the four dimensions of espoused national culture, espoused uncertainty avoidance plays the most crucial role. Additionally, the two constructs of trust were both found to be significant direct relationships with intentions. Interaction effects of trust and uncertainty avoidance were found to be significant, which suggests that researchers should consider the interaction effect of trust and the espoused cultural values in future research. 


\section{REFERENCES}

Abramova, O., Shavanova, T., Fuhrer, A., Krasnova, H., \& Buxmann, P. (2015). Understanding the sharing economy: The role of response to negative reviews in the peer-to-peer accommodation sharing network. Proceedings of Twenty-Third European Conference on Information Systems (ECIS).

Airbnb. (2018). Airbnb: Fast Facts. https://press.atairbnb.com/fast-facts

Ajzen, I. (1985). From intentions to actions: A theory of planned behavior. In Action control (pp. 11-39). Springer. doi:10.1007/978-3-642-69746-3_2

Al-Gahtani, S. S. (2003). Computer technology adoption in Saudi Arabia: Correlates of perceived innovation attributes. Information Technology for Development, 10(1), 57-69. doi:10.1002/itdj.1590100106

Allen, J. P. (2017). Technology and Inequality Case Study: The Sharing Economy. In Technology and Inequality (pp. 121-135). Palgrave Macmillan. doi:10.1007/978-3-319-56958-1_8

Bardhi, F., \& Eckhardt, G. M. (2012). Access-based consumption: The case of car sharing. The Journal of Consumer Research, 39(4), 881-898. doi:10.1086/666376

Belk, R. (2010). Sharing. The Journal of Consumer Research, 36(5), 715-734. doi:10.1086/612649

Belk, R. (2014). You are what you can access: Sharing and collaborative consumption online. Journal of Business Research, 67(8), 1595-1600. doi:10.1016/j.jbusres.2013.10.001

Bergh, A., \& Funcke, A. (2016). Does country level social trust predict the size of the sharing economy? (No. 1130). IFN Working Paper.

Botsman, R. (2012). The currency of the new economy is trust 1 TED Talk. https://www.ted.com/talks/rachel_ botsman_the_currency_of_the_new_economy_is_trust

Botsman, R., \& Rogers, R. (2010). What's mine is yours: The rise of collaborative consumption. Collins.

Calhoun, K. J., Teng, J. T., \& Cheon, M. J. (2002). Impact of national culture on information technology usage behaviour: An exploratory study of decision making in Korea and the USA. Behaviour \& Information Technology, 21(4), 293-302. doi:10.1080/0144929021000013491

Chang, Y. W., Hsu, P. Y., Shiau, W. L., \& Tsai, C. C. (2015). Knowledge sharing intention in the United States and China: A cross-cultural study. European Journal of Information Systems, 24(3), 262-277. doi:10.1057/ ejis.2014.28

Chin, W. W. (1998). Commentary: Issues and opinion on structural equation modeling. Management Information Systems Quarterly, 22(1), 7-16.

Chin, W. W., Marcolin, B. L., \& Newsted, P. R. (2003). A partial least squares latent variable modeling approach for measuring interaction effects: Results from a Monte Carlo simulation study and an electronic-mail emotion/ adoption study. Information Systems Research, 14(2), 189-217. doi:10.1287/isre.14.2.189.16018

Chu, X., Luo, X. R., \& Chen, Y. (2019). A systematic review on cross-cultural information systems research: Evidence from the last decade. Information \& Management, 56(3), 403-417. doi:10.1016/j.im.2018.08.001

Cyr, D., Head, M., Larios, H., \& Pan, B. (2009). Exploring human images in website design: A multi-method approach. Management Information Systems Quarterly, 33(3), 539-566. doi:10.2307/20650308

Davis, F. D. (1989). Perceived usefulness, perceived ease of use, and user acceptance of information technology. Management Information Systems Quarterly, 13(3), 319-340. doi:10.2307/249008

Dibbern, J., Chin, W. W., \& Heinzl, A. (2012). Systemic determinants of the information systems outsourcing decision: A comparative study of German and United States firms. Journal of the Association for Information Systems, 13(6), 1. doi:10.17705/1jais.00298

Dinev, T., Goo, J., Hu, Q., \& Nam, K. (2009). User behaviour towards protective information technologies: The role of national cultural differences. Information Systems Journal, 19(4), 391-412. doi:10.1111/j.13652575.2007.00289.x 
Dorfman, P. W., \& Howell, J. P. (1988). Dimensions of national culture and effective leadership patterns: Hofstede revisited. Advances in International Comparative Management, 3(1), 127-150.

Ert, E., Fleischer, A., \& Magen, N. (2016). Trust and reputation in the sharing economy: The role of personal photos in Airbnb. Tourism Management, 55, 62-73. doi:10.1016/j.tourman.2016.01.013

Evaristo, J., \& Karahanna, E. (1998). The Impact of Privatization on Organizational Information Needs: Lessons from the Brazilian Telecommunications Holding Company. Information Technology \& People, 11(3), $207-216$. doi:10.1108/09593849810228002

Fishbein, M., \& Ajzen, I. (1977). Belief, attitude, intention, and behavior: An introduction to theory and research. Journal of Business Venturing, 5, 177-189.

Fornell, C., \& Larcker, D. F. (1981). Evaluating structural equation models with unobservable variables and measurement error. JMR, Journal of Marketing Research, 18(1), 39-50. doi:10.1177/002224378101800104

Friedman, T. L. (2005). The world is flat: A brief history of the twenty-first century. Macmillan.

Gefen, D., Karahanna, E., \& Straub, D. W. (2003). Trust and TAM in online shopping: An integrated model. Management Information Systems Quarterly, 27(1), 51-90. doi:10.2307/30036519

Guttentag, D. (2015). Airbnb: Disruptive innovation and the rise of an informal tourism accommodation sector. Current Issues in Tourism, 18(12), 1192-1217. doi:10.1080/13683500.2013.827159

Guttentag, D. A., \& Smith, S. L. (2017). Assessing Airbnb as a disruptive innovation relative to hotels: Substitution and comparative performance expectations. International Journal of Hospitality Management, 64, 1-10. doi:10.1016/j.ijhm.2017.02.003

Haapaniemi, T. P., \& Makinen, S. J. (2009). Moderating effect of national attributes and the role of cultural dimensions in technology adoption takeoff. Management Research News, 23(1), 5-25. doi:10.1108/01409170910921998

Hall, E. T. (1989). Beyond culture. Anchor.

Hamari, J., Sjoklint, M., \& Ukkonen, A. (2016). The sharing economy: Why people participate in collaborative consumption. Journal of the Association for Information Science and Technology, 67(9), 2047-2059. doi:10.1002/ asi. 23552

Hoehle, H., Zhang, X., \& Venkatesh, V. (2015). An espoused cultural perspective to understand continued intention to use mobile applications: A four-country study of mobile social media application usability. European Journal of Information Systems, 24(3), 337-359. doi:10.1057/ejis.2014.43

Hofstede, G. (1980). Culture Consequences: International Differences in Work-Related Values. Sage Publications.

Hofstede, G. (1983). National cultures in four dimensions: A research-based theory of cultural differences among nations. International Studies of Management \& Organization, 13(1-2), 46-74. doi:10.1080/00208825 .1983 .11656358

Hofstede, G. (2015). 10 minutes with Geert Hofstede on Uncertainty Avoidance 01032015. https://www.youtube. com/watch?v=fZF6LyGne7Q

Hofstede, G. (n.d.). National Culture - Hofstede Insights. Hofstede Insights. https:/www.hofstede-insights.com/ models/national-culture/

Hofstede, G., \& Bond, M. H. (1988). The Confucius connection: From cultural roots to economic growth. Organizational Dynamics, 16(4), 5-21. doi:10.1016/0090-2616(88)90009-5

Horton, J. J., \& Zeckhauser, R. J. (2016). Owning, using and renting: some simple economics of the "sharing economy” (No. w22029). National Bureau of Economic Research. https://www.nber.org/papers/w22029

Huurne, M., Ronteltap, A., Corten, R., \& Buskens, V. (2017). Antecedents of trust in the sharing economy: A systematic review. Journal of Consumer Behaviour, 16(6), 485-498. doi:10.1002/cb.1667

Jones, M. C., Cline, M., \& Ryan, S. (2006). Exploring knowledge sharing in ERP implementation: An organizational culture framework. Decision Support Systems, 41(2), 411-434. doi:10.1016/j.dss.2004.06.017 
Karahanna, E., Evaristo, J. R., \& Srite, M. (2005). Levels of culture and individual behavior: An investigative perspective. Journal of Global Information Management, 13(2), 1-20. doi:10.4018/jgim.2005040101

Kelman, H. C. (1958). Compliance, identification, and internalization three processes of attitude change. The Journal of Conflict Resolution, 2(1), 51-60. doi:10.1177/002200275800200106

Kim, J., Yoon, Y., \& Zo, H. (2015). Why People Participate in the Sharing Economy: A Social Exchange Perspective. PACIS, 76.

Kroeber, A. L. (1952). The nature of culture. University of Chicago Press.

Lee, I., Choi, B., Kim, J., \& Hong, S. J. (2007). Culture-technology fit: Effects of cultural characteristics on the post-adoption beliefs of mobile internet users. International Journal of Electronic Commerce, 11(4), 11-51. doi:10.2753/JEC1086-4415110401

Leidner, D. E., \& Kayworth, T. (2006). A review of culture in information systems research: Toward a theory of information technology culture conflict. Management Information Systems Quarterly, 30(2), 357-399. doi: $10.2307 / 25148735$

Li, X., Hess, T. J., McNab, A. L., \& Yu, Y. (2009). Culture and acceptance of global web sites: A cross-country study of the effects of national cultural values on acceptance of a personal web portal. ACM SIGMIS Database: the DATABASE for Advances in Information Systems, 40(4), 49-74. doi:10.1145/1644953.1644959

Lin, H. Y., Wang, M. H., \& Wu, M. J. (2017). A study of Airbnb use behavior in the sharing economy. International Journal of Organizational Innovation, 10(1), 38-47.

Liu, Y., Nie, L., \& Li, L. (2016). Homogeneity, trust, and reciprocity: Three keys to the sustainable hospitality exchange of couchsurfing. Tourism Analysis, 21(2-3), 145-157. doi:10.3727/108354216X14559233984610

Lock, S. (2019). Number of sharing economy users in the U.S. 2016-2021. https://www.statista.com/ statistics/289856/number-sharing-economy-users-us/

Marcus, A., \& Gould, E. W. (2000). Crosscurrents: Cultural dimensions and global Web user-interface design. Interaction, 7(4), 32-46. doi:10.1145/345190.345238

Mayer, R. C., Davis, J. H., \& Schoorman, F. D. (1995). An integrative model of organizational trust. Academy of Management Review, 20(3), 709-734. doi:10.5465/amr.1995.9508080335

Mazareanu, E. (2019). Values of the global sharing economy 2014-2025. https://www.statista.com/ statistics/830986/value-of-the-global-sharing-economy/

McCoy, S., Everard, A., \& Jones, B. M. (2005). An examination of the technology acceptance model in Uruguay and the US: A focus on culture. Journal of Global Information Technology Management, 8(2), 27-45. doi:10. 1080/1097198X.2005.10856395

Mcknight, D. H., Carter, M., Thatcher, J. B., \& Clay, P. F. (2011). Trust in a specific technology: An investigation of its components and measures. ACM Transactions on Management Information Systems, 2(2), 12. doi: $10.1145 / 1985347.1985353$

McKnight, D. H., \& Chervany, N. L. (2001). What trust means in e-commerce customer relationships: An interdisciplinary conceptual typology. International Journal of Electronic Commerce, 6(2), 35-59. doi:10.108 0/10864415.2001.11044235

McKnight, D. H., Cummings, L. L., \& Chervany, N. L. (1998). Initial trust formation in new organizational relationships. Academy of Management Review, 23(3), 473-490. doi:10.5465/amr.1998.926622

Mittendorf, C. (2016). What trust means in the Sharing Economy: A provider perspective on Airbnb.com. Proceedings of the 22nd Americas Conference on Information Systems.

Nakata, C., \& Sivakumar, K. (1996). National culture and new product development: An integrative review. Journal of Marketing, 60(1), 61-72. doi:10.1177/002224299606000106

New York City Department of City Planning. (2017). NYC Hotel Market Analysis, Existing Conditions and 10-year Outlook. https://www1.nyc.gov/assets/planning/download/pdf/plans-studies/m1-hotel-text/nyc-hotelmarket-analysis.pdf? $\mathrm{r}=\mathrm{a}$ 
Nunnally, J. C. (1994). Psychometric theory 3E. Tata McGraw-Hill Education.

O'Regan, M., \& Choe, J. (2017). Airbnb and cultural capitalism: Enclosure and control within the sharing economy. Anatolia, 28(2), 163-172. doi:10.1080/13032917.2017.1283634

Ou, C. X., \& Davison, R. M. (2009). Technical opinion Why eBay lost to TaoBao in China: The Glocal advantage. Communications of the ACM, 52(1), 145-148. doi:10.1145/1435417.1435450

Pavlou, P. A., \& Chai, L. (2002). What drives electronic commerce across cultures? Across-cultural empirical investigation of the theory of planned behavior. Journal of Electronic Commerce Research, 3(4), $240-253$.

Pavlou, P. A., \& Gefen, D. (2004). Building effective online marketplaces with institution-based trust. Information Systems Research, 15(1), 37-59. doi:10.1287/isre.1040.0015

Qi, C., \& Chau, P. Y. (2015). Relationship or contract? Exploring the key factor leading to IT outsourcing success in China. Information Technology \& People, 28(3), 466-499. doi:10.1108/ITP-10-2014-0236

Reinecke, K., \& Bernstein, A. (2013). Knowing what a user likes: A design science approach to interfaces that automatically adapt to culture. Management Information Systems Quarterly, 37(2), 427-453. doi:10.25300/ MISQ/2013/37.2.06

Rose, G., \& Straub, D. (1998). Predicting general IT use: Applying TAM to the Arabic world. Journal of Global Information Management, 6(3), 39-46. doi:10.4018/jgim.1998070104

Rosseel, Y. (2012). Lavaan: An R package for structural equation modeling and more. Version 0.5-12 (BETA). Journal of Statistical Software, 48(2), 1-36. doi:10.18637/jss.v048.i02

Rousseau, D. M., Sitkin, S. B., Burt, R. S., \& Camerer, C. (1998). Not so different after all: A cross-discipline view of trust. Academy of Management Review, 23(3), 393-404. doi:10.5465/amr.1998.926617

Sang-Hun, C. (2007). To outdo Google, Naver taps into Korea's collective wisdom. International Herald Tribune.

Sia, C. L., Lim, K. H., Leung, K., Lee, M. K., Huang, W. W., \& Benbasat, I. (2009). Web strategies to promote internet shopping: Is cultural-customization needed? Management Information Systems Quarterly, 33(3), 491-512. doi:10.2307/20650306

Singh, N., Zhao, H., \& Hu, X. (2003). Cultural adaptation on the web: A study of American companies' domestic and Chinese websites. Journal of Global Information Management, 11(3), 63-80. doi:10.4018/jgim.2003070104

Singh, S. (2006). Cultural differences in, and influences on, consumers' propensity to adopt innovations. International Marketing Review, 23(2), 173-191. doi:10.1108/02651330610660074

Smith, C. (2018). 100 Airbnb statistics and facts (February 2018)। By the numbers. https://expandedramblings. com/index.php/airbnb-statistics/

Sondergaard, M. (1994). Research note: Hofstede's consequences: a study of reviews, citations and replications. Organization Studies, 15(3), 447-456. doi:10.1177/017084069401500307

Srite, M., \& Karahanna, E. (2006). The role of espoused national cultural values in technology acceptance. Management Information Systems Quarterly, 30(3), 679-704. doi:10.2307/25148745

Statista Research Department. (2016). Number of lodging sharing economy users in the US 2014-2020. Statista. https://www.statista.com/statistics/292556/number-lodging-sharing-economy users-us/

Straub, D., Loch, K., Evaristo, R., Karahanna, E., \& Srite, M. (2002). Toward a theory-based measurement of culture. Journal of Global Information Management, 10(1), 13-23. doi:10.4018/jgim.2002010102

Sundararajan, A. (2016). The sharing economy: The end of employment and the rise of crowd-based capitalism. MIT Press.

Sutherland, W., \& Jarrahi, M. H. (2018). The sharing economy and digital platforms: A review and research agenda. International Journal of Information Management, 43, 328-341. doi:10.1016/j.ijinfomgt.2018.07.004

Thatcher, J. B., Stepina, L. P., Srite, M., \& Liu, Y. (2003). Culture, overload and personal innovativeness with information technology: Extending the nomological net. Journal of Computer Information Systems, 44(1), 74-81. 
Triandis, H. C. (1989). The self and social behavior in differing cultural contexts. Psychological Review, 96(3), 506-520. doi:10.1037/0033-295X.96.3.506

Ufford, S. (2015). The future of the sharing economy depends on trust. http://www.forbes.com/sites/ theyec/2015/02/10/thefuture-of-the-sharing economy-depends-on-trust/\#4dfefd0f58ff

Veiga, J. F., Floyd, S., \& Dechant, K. (2001). Towards modelling the effects of national culture on IT implementation and acceptance. Journal of Information Technology, 16(3), 145-158. doi:10.1080/02683960110063654

Venkatesh, V., \& Davis, F. D. (2000). A theoretical extension of the technology acceptance model: Four longitudinal field studies. Management Science, 46(2), 186-204. doi:10.1287/mnsc.46.2.186.11926

Venkatesh, V., \& Morris, M. G. (2000). Why don't men ever stop to ask for directions? Gender, social influence, and their role in technology acceptance and usage behavior. Management Information Systems Quarterly, 24(1), 115-139. doi:10.2307/3250981

Venkatesh, V., Morris, M. G., Davis, G. B., \& Davis, F. D. (2003). User acceptance of information technology: Toward a unified view. Management Information Systems Quarterly, 27(3), 425-478. doi:10.2307/30036540

Venkatesh, V., Thong, J. Y., \& Xu, X. (2012). Consumer acceptance and use of information technology: Extending the unified theory of acceptance and use of technology. Management Information Systems Quarterly, 36(1), 157-178. doi:10.2307/41410412

Venkatesh, V., \& Zhang, X. (2010). Unified theory of acceptance and use of technology: US vs. China. Journal of Global Information Technology Management, 13(1), 5-27. doi:10.1080/1097198X.2010.10856507

Zhou, Z., Jin, X. L., Fang, Y., \& Vogel, D. (2015). Toward a theory of perceived benefits, affective commitment, and continuance intention in social virtual worlds: Cultural values (indulgence and individualism) matter. European Journal of Information Systems, 24(3), 247-261. doi:10.1057/ejis.2014.27 


\section{APPENDIX A}

\section{Survey Items}

\section{Scoring}

Power Distance

Scores nearer to 7 are high power distance while score closer to 1 are low power distance.

Individualism/Collectivism

Scores nearer to 7 are more collectivistic while score closer to 1 are more individualistic.

\section{Masculinity/Femininity}

Scores nearer to 7 are more masculine while score closer to 1 are more feminine.

Uncertainty Avoidance

Scores nearer to 7 are high uncertainty avoidance while score closer to 1 are low uncertainty avoidance.

\section{APPENDIX B}

Descriptive Statistics of Observed Variables 
Table 5. Questionnaire Items

\begin{tabular}{|c|c|}
\hline Behavioral Intention to use & \\
\hline [BI1] I intend to use Sharing Hospitality Online Platforms in the future. & Venkatesh et al. (2012) \\
\hline $\begin{array}{l}\text { [BI2] I will always try to use Sharing Hospitality Online Platforms when I am searching for } \\
\text { accommodations. }\end{array}$ & Venkatesh et al. (2012) \\
\hline $\begin{array}{l}\text { [BI3] I plan to use Sharing Hospitality Online Platforms frequently when searching for } \\
\text { accommodations. }\end{array}$ & Venkatesh et al. (2012) \\
\hline \multicolumn{2}{|l|}{ Perceived Usefulness } \\
\hline $\begin{array}{l}\text { [PU1] I feel that Sharing Hospitality Online Platforms can provide me accurate and enough information } \\
\text { about the users' reputation. }\end{array}$ & Pavlou \& Gefen (2004) \\
\hline $\begin{array}{c}\text { [PU2] A considerable amount of useful feedback information about the transaction history of different } \\
\text { users is available through Sharing Hospitality Online Platforms. }\end{array}$ & Pavlou \& Gefen (2004) \\
\hline $\begin{array}{l}\text { [PU3] I found using Online Sharing Hospitality Platforms can improve my effectiveness when I am } \\
\text { searching for accommodations. }\end{array}$ & Srite \& Karahanna (2006) \\
\hline [PU4] I believe that the Online Sharing Hospitality Platform I used is reliable and dependable. & Pavlou \& Gefen (2004) \\
\hline \multicolumn{2}{|l|}{ Perceived Ease of Use } \\
\hline [PEOU1] It is easy for me to become skillful in using Online Sharing Hospitality Platforms. & Srite \& Karahanna (2006) \\
\hline [PEOU2] I found Online Sharing Hospitality Platforms easy to use. & Srite \& Karahanna (2006) \\
\hline [PEOU3] The interaction with Online Sharing Hospitality Platforms is clear and understandable for me. & Venkatesh et al. (2012) \\
\hline [PEOU4] Learning to operate an Online Sharing Hospitality Platform is easy for me. & Srite \& Karahanna (2006) \\
\hline \multicolumn{2}{|l|}{ Subjective Norms } \\
\hline $\begin{array}{l}\text { [SN1] My relatives think that I should use an Online Sharing Hospitality Platform when I need } \\
\text { accommodations. }\end{array}$ & Srite \& Karahanna (2006) \\
\hline $\begin{array}{l}\text { [SN2] My friends recommend me to use an Online Sharing Hospitality Platform when I need } \\
\text { accommodations. }\end{array}$ & Srite \& Karahanna (2006) \\
\hline [SN3] I believe use an Online Sharing Hospitality Platform would improve my image among my peers. & Moore \& Benbasat (1991) \\
\hline [SN4] My colleagues or classmates think I should use an Online Sharing Hospitality Platform. & Srite \& Karahanna (2006) \\
\hline \multicolumn{2}{|l|}{ Trust-Situational Normality-I } \\
\hline [TSN1] I am totally comfortable living live in strangers' residence. & McKnight et al. (2011) \\
\hline [TSN2] I feel very good about living in strangers' residence. & McKnight et al. (2011) \\
\hline [TSN3] I am confident that everything will go as my expectations when I live in strangers' residence. & McKnight et al. (2011) \\
\hline [TSN4] It appears that things will be fine when I live in strangers' residence. & McKnight et al. (2011) \\
\hline \multicolumn{2}{|l|}{ Trust-Situational Normality-II } \\
\hline [TSN1] I am totally comfortable sharing living spaces with other strangers. & McKnight et al. (2011) \\
\hline [TSN2] I feel very good about sharing living spaces with other strangers. & McKnight et al. (2011) \\
\hline $\begin{array}{l}\text { [TSN3] I am confident that everything will go as my expectations when I share living spaces with other } \\
\text { strangers. }\end{array}$ & McKnight et al. (2011) \\
\hline [TSN4] It appears that things will be fine when I share living spaces with other strangers. & McKnight et al. (2011) \\
\hline \multicolumn{2}{|l|}{ Trust-Structural Assurance } \\
\hline $\begin{array}{l}\text { [TSA1] I feel okay using Online Sharing Hospitality Platforms because they are backed by vendor } \\
\text { protections. }\end{array}$ & McKnight et al. (2011) \\
\hline [TSA2] Customer service make it feel all right to use Online Sharing Hospitality Platforms. & McKnight et al. (2011) \\
\hline $\begin{array}{l}\text { [TSA3] Favorable-to-customer legal structures help me feel safe working with Online Sharing } \\
\text { Hospitality Platforms. }\end{array}$ & McKnight et al. (2011) \\
\hline $\begin{array}{l}\text { [TSA4] Having the backing of legal statues and processes makes me feel secure in using Online Sharing } \\
\text { Hospitality Platforms. }\end{array}$ & McKnight et al. (2011) \\
\hline \multicolumn{2}{|l|}{ Individualism/Collectivism } \\
\hline \multicolumn{2}{|l|}{$\begin{array}{l}\text { [IC1] Being accepted as a member of a group is more important than having autonomy and } \\
\text { independence on the job. }\end{array}$} \\
\hline \multicolumn{2}{|l|}{ [IC2] Group success is more important than individual success. } \\
\hline \multicolumn{2}{|l|}{ [IC3] It is more important for a manager to encourage loyalty and a sense of duty individual initiative. } \\
\hline \multicolumn{2}{|l|}{ [IC4] Individual rewards are not as important as group welfare. } \\
\hline \multicolumn{2}{|l|}{ Masculinity/Femininity } \\
\hline \multicolumn{2}{|l|}{$\begin{array}{l}\text { [MF1] Having challenging work to do is a more important work goal than having a friendly work } \\
\text { atmosphere. }\end{array}$} \\
\hline $\begin{array}{c}\text { [MF2] Getting the recognition you deserve when you do a good job is a more important work goal than } \\
\text { employment security. }\end{array}$ & \\
\hline
\end{tabular}


Table 5. Continued

\begin{tabular}{|c|c|}
\hline [MF3] Prestige is a more important goal to me than having less stress at work & \\
\hline \multicolumn{2}{|l|}{$\begin{array}{l}\text { [MF4] Having challenging work to do is a more important work goal than having a good working } \\
\text { relationship with your manager }\end{array}$} \\
\hline \multicolumn{2}{|l|}{$\begin{array}{l}\text { [MF5] Having challenging work to do is a more important work goal than working with people who } \\
\text { cooperate well with each other }\end{array}$} \\
\hline \multicolumn{2}{|l|}{ Uncertainty Avoidance } \\
\hline \multicolumn{2}{|l|}{$\begin{array}{l}\text { [UA1] Rules and regulations are important because they inform workers what the organization expects } \\
\text { of them. }\end{array}$} \\
\hline \multicolumn{2}{|l|}{$\begin{array}{l}\text { [UA2] It is better to have a bad situation that you know about, then to have an uncertain situation that } \\
\text { might be better }\end{array}$} \\
\hline \multicolumn{2}{|l|}{$\begin{array}{l}\text { [UA3] Providing opportunities to be innovative is less important than requiring standardized work } \\
\text { procedures. }\end{array}$} \\
\hline \multicolumn{2}{|l|}{ [UA4] People should avoid making changes because things could get worse. } \\
\hline \multicolumn{2}{|l|}{$\begin{array}{l}\text { [UA5] It is important to have job requirements and instructions spelled out in detail so that people } \\
\text { always know what they are expected to do. }\end{array}$} \\
\hline \multicolumn{2}{|l|}{ Power Distance } \\
\hline \multicolumn{2}{|l|}{$\begin{array}{c}\text { [PD1] A manager should perform work that is difficult and important and delegate tasks that are } \\
\text { repetitive and mundane to subordinates. }\end{array}$} \\
\hline \multicolumn{2}{|l|}{$\begin{array}{l}\text { [PD2] Higher-level managers should receive more benefits and privileges than lower-level managers } \\
\text { and professional staff. }\end{array}$} \\
\hline $\begin{array}{l}\text { [PD3] Managers should be careful not to ask the opinions of subordinates too frequently otherwise the } \\
\text { manager might appear to be weak and incompetent. }\end{array}$ & \\
\hline [PD4] Managers should make most decisions without consulting subordinates. & \\
\hline
\end{tabular}


Table 6. Descriptive Statistics of Observed Variables

\begin{tabular}{|c|c|c|c|c|}
\hline Variable & Mean & SD & $\min$ & $\max$ \\
\hline BI1 & 4.3 & 1.56 & 1 & 7 \\
\hline BI2 & 4.16 & 1.63 & 1 & 7 \\
\hline IC1 & 4 & 1.54 & 1 & 7 \\
\hline IC2 & 4.55 & 1.62 & 1 & 7 \\
\hline IC3 & 4.61 & 1.64 & 1 & 7 \\
\hline MF1 & 3.58 & 1.54 & 1 & 7 \\
\hline MF2 & 3.74 & 1.49 & 1 & 7 \\
\hline MF5 & 3.6 & 1.5 & 1 & 7 \\
\hline PD1 & 3.03 & 1.57 & 1 & 7 \\
\hline PD2 & 3.41 & 1.78 & 1 & 7 \\
\hline PEOU1 & 4.77 & 1.55 & 1 & 7 \\
\hline PEOU2 & 4.6 & 1.47 & 1 & 7 \\
\hline PEOU3 & 4.69 & 1.36 & 1 & 7 \\
\hline PEOU4 & 4.56 & 1.58 & 1 & 7 \\
\hline PU1 & 4.51 & 1.42 & 1 & 7 \\
\hline PU2 & 4.69 & 1.43 & 1 & 7 \\
\hline PU3 & 4.7 & 1.32 & 1 & 7 \\
\hline PU4 & 4.63 & 1.4 & 1 & 7 \\
\hline SN1 & 4.08 & 1.45 & 1 & 7 \\
\hline SN2 & 3.5 & 1.5 & 1 & 7 \\
\hline SN3 & 4.18 & 1.69 & 1 & 7 \\
\hline SN4 & 3.7 & 1.67 & 1 & 7 \\
\hline TSA1 & 5.13 & 1.4 & 1 & 7 \\
\hline TSA2 & 4.86 & 1.46 & 1 & 7 \\
\hline TSA3 & 4.59 & 1.33 & 1 & 7 \\
\hline TSA4 & 4.55 & 1.46 & 1 & 7 \\
\hline TSNI1 & 4.02 & 1.63 & 1 & 7 \\
\hline TSNI2 & 3.88 & 1.61 & 1 & 7 \\
\hline TSNI3 & 3.74 & 1.6 & 1 & 7 \\
\hline TSNI4 & 3.73 & 1.79 & 1 & 7 \\
\hline TSNII1 & 3.82 & 1.66 & 1 & 7 \\
\hline TSNII2 & 3.44 & 1.64 & 1 & 7 \\
\hline TSNII3 & 3.51 & 1.65 & 1 & 7 \\
\hline TSNII4 & 3.26 & 1.65 & 1 & 7 \\
\hline UA1 & 5.2 & 1.53 & 1 & 7 \\
\hline UA5 & 5.34 & 1.46 & 1 & 7 \\
\hline
\end{tabular}


Cong Zhang is a Ph.D. student in Information Technology Management at the University of Wisconsin Milwaukee. He received his MS in Electronic Business and Knowledge Management from the City University of Hong Kong. His research interests are the Sharing Economy, online customer reviews, and the Internet of Things.

Mark Srite received his PhD from Florida State University and is currently an Associate Professor in the Information Technology Management area and Director of Accreditation for the Lubar School of Business at the University of Wisconsin-Milwaukee. His research focuses primarily on the intersection of technology and culture and has been published in a number of journals including: Management Information Systems Quarterly, the Journal of Management Information Systems, the Journal of the AIS, Decision Support Systems, Information \& Management, etc. 